NBER WORKING PAPER SERIES

\title{
EVALUATING LABOUR ADJUSTMENT COSTS \\ FROM TRADE SHOCKS: ILLUSTRATIONS \\ FOR THE U.S. ECONOMY USING AN \\ APPLIED GENERAL EQUILIBRIUM MODEL WITH TRANSACTIONS COSTS
}

\author{
Ramon L. Clarete \\ Irene Trela \\ John Whalley
}

Working Paper No. 4628

\author{
NATIONAL BUREAU OF ECONOMIC RESEARCH \\ 1050 Massachusetts Avenue \\ Cambridge, MA 02138 \\ January 1994
}

We are grateful to the Donner Canadian Foundation for financial suppon of a North American trade project on which this work draws, and to Tom Rutherford both for comments and for use of his MPS/GE equilibrium solution algorithm. An earlier paper containing the analytical framework was presented to an NBER Applied General Equilibrium Conference held at Stanford University in May 1990. This paper is part of NBER's research program in International Trade and Investment. Any opinions expressed are those of the authors and not those of the National Bureau of Economic Research. 
NBER Working Paper \#4628

January 1994

\title{
EVALUATING LABOUR ADJUSTMENT COSTS FROM TRADE SHOCKS: ILLUSTRATIONS \\ FOR THE U.S. ECONOMY USING AN \\ APPLIED GENERAL EQUILIBRIUM MODEL WTTH TRANSACTIONS COSTS
}

\begin{abstract}
This paper presents a general equilibrium approach to calculating labour adjustment costs induced by trade policy changes or external sector shocks, which we illustrate by analyzing the adjustment consequences of eliminating quotas and tariffs on U.S. imports. In our approach, factor adjustments in the presence of transactions costs are endogenously determined within the equilibrium structure. The conventional way of calculating such labour adjustment costs is to use full equilibrium models which exclude adjustment costs, and apply exogenous estimates of duration of unemployment to implied intersectoral labour reallocations. By using an equilibrium model in which adjustment costs are absent, the conventional approach tends to overstate the amount of labour that moves to other sectors and hence introduces an upward bias to estimates of adjustment costs. As well, such an approach tends to ignore the impact on intersectoral wage rates. Our results suggest that concems over adjustment problems should focus as much on the consequences of adjustment costs in impeding factor mobility, as on the magnitude of the adjustment costs themselves. Compared to the redistributive effects they induce by inhibiting labour movement in response to policy or other changes, these costs may be small.

Ramon L. Clarete

School of Economics

University of the Philippines

Diliman, Quezon City

PHILIPPINES

John Whalley

Department of Economics

University of Westem Ontario

London, Ontario N6A 5C2

CANADA

and NBER

Irene Trela

Departruent of Economics

University of Westem Ontario

London, Ontario N6A 5C2

CANADA
\end{abstract}




\section{Introduction}

This paper argues that the evaluation of adjustment costs associated with changes in trade policies or other external sector shocks, such as import surges, requires a full equilibrium framework in which both long-term intersectoral reallocations and short-term adjustment costs from policy changes are endogenously determined. In particular, it suggests that exercises such as Cline et al. (1978), Baldwin, Mutti and Richardson (1980), or de Melo and Tar (1988) tend to overstate the adjustment costs actually involved because they use estimates of intersectoral factor reallocations generated from models in which adjustment costs do not formally appear, but to which they are then added in a separate calculation.

This is because they first calculate the amount of labour which moves between industries in long-run equilibrium assuming no adjustment costs, and then graft on a further calculation of what adjustment costs might be implied by this change in equilibrium behaviour, using estimates of the average duration of unemployment; we term this the full equilibrium plus duration approach. If instead an equilibrium model in which adjustment costs explicitly appear is used, a smaller number of workers will typically be shown as moving between industries in response to trade shocks, and adjustment costs will be correspondingly smaller. Indeed, the larger the costs of relocating between industries, the more that trade shocks are reflected in changes in relative wages between industries rather than in intersectoral reallocations of labour. This suggests that current adjusiment cost analyses may be over-focused on efficiency rather than distributional issues. 
To make our argument, we develop an economy-wide equilibrium modelling approach in which adjustment costs are endogenously determined. ${ }^{1}$ In the model, adjustment costs arise from any movement of factors between industries, and are reflected in a per-unit requirement of transactions services for any factor so moved. These services can be interpreted as search and/or retraining costs, as well as wages forgone during the unemployment period for labour. Under this treatment, the adjusting factor is quasi-fixed and a market clearing price for transaction services is endogenously determined. This transaction services requirement for any relocating factor drives a wedge between the user cost of factors in expanding sectors, and the rewards received by factor owners in contracting sectors. We can then compare adjustment costs calculated using this modelling approach and those estimated using full equilibrium plus duration methods.

We explore the implications of the differences between these two approaches by calculating labour adjustment costs in a model of U.S.-Mexican-Rest of the World trade, used recently by Trela and Whalley (forthcoming) to analyze trade implications of liberalization under NAFTA and adapted here to incorporate adjustment costs. The need for adjustments arises in the model from the elimination of quotas and tariffs on U.S. imports. The differences between the approaches in the adjustment cost estimates we report emphasize the points we make above.

'This equilibrium structure is related to that used by Foley (1970) to examine equilibrium with costly marketing, but differs both in considering adjustment costs in factor markets and in simultaneously modelling goods and factor markets. The formulation is also related to that developed by Nguyen and Whalley (1986), who use a fixed price equilibrium approach for a pure exchange economy in which transactions costs are endogenously determined. 
The organization of the paper is as follows. We first outline how labour adjustment costs can be incorporated into a general equilibrium model, also indicating how our formulation can be generalized to capture choices among adjustment options for workers, such as retraining programs of varying duration. We then describe the model, the data and functional forms used in implementing our approach for the analysis of labour adjustment costs for the trade policy change we consider. A final section reports and interprets adjustment cost estimates from elimination of quotas and tariffs on U.S. imports. 


\section{A General Equilibrium Model With Intersectorally Partially Mobile Labour and} Adjustment Costs

In this section, we describe a general equilibrium model in which labour is imperfectly mobile between sectors. The model specifies $N$ goods-producing sectors and a single sector producing transactions services. Each sector uses two factor inputs: capital and labour. Capital is assumed to be perfectly mobile between sectors, but for labour to move from one sector to another, transactions services must be used. In a real world application, this might reflect a period of unemployment faced by any relocating factor.

The cost of using these services drives a wedge between the buying price of labour in expanding industries and the selling price of labour in contracting industries. Workers trade off their longer term gains from higher wage rates over their remaining working life if they move, against the short-run cost of relocating. The time period for the model thus corresponds to the time horizon for workers in making relocation decisions; i.e., the period covered by the model is a number of years rather than a single year. The transactions services requirement to move labour reflects search time, relocation costs, and other factors. The initial allocations of labour by industry are parameters of the model.

More formally, production functions for the $N$ goods-producing and the transactions services sectors are given by:

$$
\begin{aligned}
& Q_{i}=Q_{i}\left(K_{i}, L_{i}\right) \quad i=1,2, \ldots, N \\
& T^{S}=T\left(K_{T}, L_{T}\right)
\end{aligned}
$$

where $Q_{i}$ is the output of good i. $\eta^{S}$ represents transactions services produced, $K_{i}$ and $L_{i}$ are capital and labour used by sector $i$, and $K_{T}$ and $L_{T}$ are similar factor usage in the 
transactions services sector (denoted by $T$ ). We assume these production functions to be continuous and linearly homogeneous in capital and labour.

Denoting the $(N+1)^{t h}$ sector as transactions services, homogeneity implies that:

$$
p_{i} Q_{i}=w_{i} L_{i}+r K_{i} \quad i=1,2, \ldots . N+1
$$

where $p_{i}$ is the price of good $i, w_{i}$ is the sector-specific wage rate in sector $i$, and $r$ is the rental price of intersectorally mobile capital.

Since in the presence of adjustment costs labour is only partially mobile between sectors, wages fail to equalize across sectors. As a result, and in contrast to conventional general equilibrium models without adjustment costs, a single-market clearing wage no longer characterizes equilibrium. $(N+I)$ sector-specific wage rates need to be specified, bul, at the same time, there are bounds on these wage rales given by the size of the adjustment costs. These, in tum, reflect the price of transactions services and the transactions service requirements in moving labour between any two sectors.

We denote the initial (pre-shock or pre-policy change) allocation of labour to sector $i$ as $\bar{L}_{i}^{s}$. The total economy-wide labour endowment is thus $\bar{L}^{s}=\sum_{i=1}^{N \cdot 1} \bar{L}_{i}^{s}$. The result of policy changes or external shocks affecting the economy may be that sector $i$ uses more than, less than, or the same amount of labour, $\bar{L}_{1}^{s}$, that is initially allocated to the sector.

For any shock or policy change, three types of sectors will result; namely,

$$
\begin{aligned}
& U=\left\{\text { sector } i \mid L_{i}=\bar{L}_{i}^{s}\right\} ; \\
& E=\left\{\text { sector } i \mid L_{i}>\bar{L}_{i}^{s_{j}}\right\} ; \\
& C=\left\{\text { sector } i \mid L_{i}<\bar{L}_{i}^{s}\right\} ; \quad \forall i ;
\end{aligned}
$$


7

where $U, E$ and $C$ refer to unchanged, expanding, and contracting sectors respectively. $U, E$ and $C$ represents a mutually exhaustive classification of sectors, and their union comprises the $N+1$ sectors in the economy.

$L_{i}$, the labour actually used in each sector after the shock or policy change, is expressed as a proportion of the initial allocation of labour in sector $i, \bar{L}_{i}^{s}$. We denote $\lambda_{i}$ as sector-specific labour utilization scalars, and hence

$$
L_{i}=\lambda \bar{L}_{i}^{s} \quad i=1,2, \ldots, N+1
$$

where $\lambda_{i} \geq 0, \forall i$. Each $\lambda_{i}$ is endogenously determined as part of the general equilibrium solution to the model, and indicates whether sector $i$ is expanding, contracting or unchanged relative to its initial use of labour. The amount of labour in the sector prior to the adjustment generating shock or policy change thus affects the equilibrium outcome in the economy.

For any given values of $L_{i}$, sector-specific wage rates can be calculated using equation (2) as,

$$
w_{1}=\frac{\left(p_{1} Q_{1}-r K_{i}\right)}{L_{t}} \quad i=1,2, \ldots . N .
$$

Given $L_{i}$ and $r, K_{i}$ is determined by the requirement that capital will be hired up to the point where its value marginal product equals the rental price of capital. This allows $w_{i}$ to be calculated using equation (5).

The costs of transactions services required to move labour between sectors establishes bounds on wage rates across sectors. Firms in expanding sectors demand labour until the value marginal product of labour equals the cost to the firm of hiring labour, which we 
denote as $w$. If the value marginal product of labour in a sector is higher than $w$, there are incentives to continue hiring labour. In tum, labour initially allocated to contracting sectors will move out of the sector and into expanding sectors until the value marginal product of labour remaining in the sector equals $w^{R}$, the reservation wage received by sellers of labour after any transactions costs. A value marginal product less than $w^{R}$ provides incentives for labour to leave contracting sectors. In unchanged sectors, the wage rate lies between $w$ and $w^{R}$, since labour is best off by remaining in the sector to which it is initially allocated. $w^{R}$ thus equals the maximum of 0 and $w-p_{T}$, where $p_{T}$ is the price of transactions services.

Wage rates by sector, reflecting these bounds, are as follows:

$w_{i}=\left\{\begin{array}{l}w \quad \forall i \in E ; \\ \min \left(w, \max \left(w_{i}, w^{R}\right)\right) \quad \forall i \in U ; \\ w^{R} \quad \forall i \in C\end{array}\right.$

Adopting, for now, the simplifying units convention that one unit of transactions services is required to move one unit of labour between sectors, the total demand for transactions services is given by:

$$
T^{D}=\underset{i \in C}{\sum}\left(\bar{L}_{i}^{s}-L_{i}\right)
$$

Assuming that consumers have identical homothetic preferences allows us to represent the demand side of the model as a single representative consumer endowed with all the labour and capital in the economy, $\bar{L}^{s}$ and $\bar{K}^{s}$. This simplification is not essential to our analytical framework, but is used here for simplicity in presentation. In numerical application, we can also consider multiple consumers, including cases where consumers are 
each separately endowed with the labour initially allocated to the various production sectors in the model.

The representative consumer is assumed to maximize a utility function defined over the $N$ goods, subject to the budget constraint

$$
\sum_{i=i}^{N} p_{i} C_{i}-\sum_{i=1}^{N+1} w \bar{L}_{i}^{s}-r \bar{K}^{s}=0
$$

The resulting utility maximum problem can be solved to determine $C_{j}$, the final demands for $\operatorname{good} i$.

Given the above, equilibrium in this model is characterized by goods and transactions service prices $p_{i}(i=1, \ldots, N+1)$, a rental price of capital $r$, a wage rate in expanding sectors $w$, and labour demand scalars, $\lambda_{j}(j=1, \ldots, N+1)$, all denoted by the vector $\varepsilon=\left(p_{j}, r, w, p_{T}, \lambda_{j}\right), i=l, \ldots, N ; j=1, \ldots, N+1$, such that a series of equilibrium conditions hold.

The first is that bounds on sector wage rates must hold; i.e.

$$
\begin{aligned}
& w_{j}(\varepsilon)=w \quad \forall j \in E ; \\
& w_{j}(\varepsilon)=\min \left[w, \max \left(w_{j}, w^{R}\right)\right] \quad \forall j \in U ; \text { and } \\
& w_{j}(\varepsilon)=w^{R} \quad \forall j \in C .
\end{aligned}
$$

The second is that demand supply equalities hold for:

(i) Consumer goods

$$
C_{i}(\varepsilon)=Q_{1}(\varepsilon) \quad i=1,2, \ldots, N
$$

(ii) Capilal

$$
\sum_{i=1}^{N+1} K_{i}(\varepsilon)=\bar{K}^{s}
$$


(iii) Labour

$$
\sum_{i=1}^{N \cdot 1} L_{l}(\varepsilon)=\bar{L}^{s}
$$

and

(iv) Transactions services

$$
T^{D}(\varepsilon)=T^{s}(\varepsilon)
$$

Equations (9) to (13) characterize an equilibrium in which there are $(2 N+4)$ endogenous variables and $(2 N+4)$ equilibrium conditions. To determine an equilibrium, values must be determined for the $N$ goods prices, the rental price of capital, the wage rate paid when hiring additional labour, the price of transactions services, and the $(N+1)$ labour demand scalars. Market clearing conditions must also apply for goods markets, the capital market, the labour market, and for transactions services. In addition, the sector-specific wage rates should be bounded from above by $w$ and from below by $w^{R}$.

The properties of the mapping whose fixed point characterizes an equilibrium in this model can be seen as follows. Rewriting the conditions (9) to (13) as functions $f_{j}(\varepsilon)$ $(i=1, \ldots 2 N+4)$, an equilibrium for the model can be alternatively characterized as a vector $\varepsilon^{*}$ such that:

$$
f\left(\varepsilon^{*}\right)=0 \text {. }
$$

The equation system $f(\varepsilon)$ operates much like a system of excess demands, which satisfy a condition akin to the traditional Walras Law. If $g(\varepsilon)$ is defined to equal $\mu \cdot f(\varepsilon)$, where $\mu_{i}=1$, for $i=1,2 \ldots, N+3$; and $\bar{L}_{i}^{s}$, for $i=N+4, \ldots .2 N+4 ;$ then $g(\varepsilon)$ has the property that $\sum_{i=1}^{2 N \cdot 4} \varepsilon_{g} g(\varepsilon)=0$, i.e. a modified version of the Walras Law holds. This property can be shown to follow directly from the model structure. 
Adding over the zero-profit conditions (2), and substituting (4) and (6) into the budget constraint (8), yields:

$$
\begin{aligned}
& \sum_{i=1}^{N} p_{i}\left(C_{i}-Q_{i}\right)+r\left(\sum_{i=1}^{N+1} K_{i}-\bar{K}^{s}\right)-p_{T} T^{s}-\sum_{i \in E} w \bar{L}_{i}^{s} \\
& -\sum_{i \in U} \min \left(w, \max \left(w_{i}, w^{N}\right)\right) \bar{L}_{i}^{s}-\sum_{i \in C} w^{R} \bar{L}_{i}^{s}+\sum_{i=1}^{N+1} w_{i} \lambda \bar{L}_{i}^{s}=0 .
\end{aligned}
$$

Adding and subtracting $w \sum_{i=1}^{W_{-1}} \lambda \bar{L}_{i}^{s} ; p_{T} \sum_{k c} \lambda \bar{L}_{i}^{s} ;$ and $w \sum_{k U} \bar{L}_{i}^{s}$ to and from both sides; and substituting ( 7 yields:

$$
\begin{gathered}
\sum_{i=1}^{N} p_{i}\left(C_{i}-Q_{i}\right)+r\left(\sum_{i=1}^{N+1} K_{i}-\bar{K}^{s}\right)+w\left(\sum_{i=1}^{N+1} L_{i}-\bar{L}^{s}\right)+p_{T}\left(T^{D}-T^{s}\right) \\
+\sum_{i \in E}\left(w_{i}-w\right) \lambda \bar{L}_{i}^{s}+\sum_{i \in U}\left(w_{i}-w\right) \lambda \bar{L}_{i}^{s}+\sum_{i \in C}\left(w-w^{R}\right) \lambda \bar{L}_{i}^{s} \\
+\sum_{i \in U}\left(w-\min \left(w, \max \left(w_{i}, w^{R}\right)\right)\right) \bar{L}_{i}^{s}=0 .
\end{gathered}
$$

By definition, $\lambda \bar{L}_{i}^{s}=\bar{L}_{i}^{s}$ if sector $i \in U$. Thus, we get the result that $\sum_{i=1}^{2 N \cdot 4} \varepsilon_{g} g_{i}(\varepsilon)=0$; i.e. $\varepsilon g(\varepsilon)=0$. The equation system (9) to (13) can be solved for $\varepsilon^{*}$ using general equilibrium solution code such as the MPS/GE software developed by Rutherford (1988), or using a conventional fixed-point algorithm such as Broadie's (1983), Merrill's (1972), or van der Laan and Talman's (1979).

The model described above can also be used to analyze labour adjustment costs for an open price-taking economy. If there are $T$ traded goods, $H$ home goods, a transactions services sector, an aggregate consumer, and a government, the total number of sectors in the model is $N=T+H+1$. Production functions for goods and transactions services sectors 
are as described above. The aggregate consumer has a utility function defined over the $(T+H)$ goods.

If world prices of trade goods are fixed and denoted by the vector $\bar{p}$, we can define a composite traded good for this model as:

$$
\begin{aligned}
& C^{c}=\sum_{i=1}^{T} \bar{p}_{1} C_{i} \quad \text { and } \\
& Q^{c}=\sum_{i=1}^{T} \bar{p}_{i} Q_{i}
\end{aligned}
$$

where $C^{C}$ and $Q^{C}$ are respectively the demand and supply of the composite traded good. We denote the price of this composite good relative to the numeraire good used in the model by p. Accordingly, the domestic prices of traded goods, $p_{i}{ }^{D}$ and are equal to $p_{i}^{D}=p \bar{p}_{i}$.

In this case, a general equilibrium is given by values $\left[r^{*}, w^{*} p_{i}^{*}(i=1,2, \ldots, H), p^{*}, \lambda_{j}{ }^{*}(j=1,2, \ldots, N)\right.$, and $\left.p_{\tau}^{*}\right]$ such that:

(i) factor markets clear

$$
\begin{aligned}
& \sum_{i=1}^{N} K_{i}-\bar{K}^{s}=0 \\
& \sum_{i=1}^{N} L_{i}-\bar{L}^{s}=0
\end{aligned}
$$

(ii) goods markets clear

$$
\begin{array}{ll}
C_{i}-Q_{i}=0 & \forall \text { homegoods; } \\
C^{c}-Q^{c}=0 ; & \text { and } \\
T^{D}-T^{S}=0 . &
\end{array}
$$


(iii) bounds on wage rates hold

$$
\begin{aligned}
& w_{j}-w=0 \quad \forall j \in E ; \\
& w_{j}-\min \left(w, \max \left(w_{,}, w^{R}\right)\right)=0 \quad \forall j \in U ; \text { and } \\
& w_{j}-w^{R}=0 \quad \forall j \in C_{i}
\end{aligned}
$$

An equilibrium in this case can also be computed using fixed-point or other solution techniques.

In presenting the models above, we have used the simplifying assumption that adjustment costs are such that one unit of transactions services is required for each unit of labour that moves between sectors. This treatment of adjustment costs can be both generalized and refined, although at some cost in complexity of notation. If the major component of adjustment costs is labour time (unemployment), then the technology for transactions services can be specified as heavily labour-intensive, or even exclusively labour using. If adjustment costs are thought to be different between pairs of industries, different transactions services requirements for moving labour between any pair of industries can be specified. In this case, optimizing behaviour by agents would involve trading off moving to high wage industries against larger adjustment costs which, in tum, could reflect any retraining required. Differential adjustment costs across different regions can also be modelled, with industries subscripted by region and with differential adjustment costs between them. Hence a range of elaborations are possible on the basic approach, which, in combination, allows for a wide range of applications of the model. 
14

\section{Analyzing Labour Adjustment Costs in a Model of U.S. Trade}

We have used the approach presented above to analyze the adjustment consequences of eliminating quotas and tariffs on U.S. imports in models with and without endogenously determined transactions costs. We employ an existing multisectoral trade model of the U.S., Mexico, and the Rest-of-the-World recently used by Trela and Whalley (forthcoming) for model-based evaluations of the impact of NAFTA. We have further elaborated this model here to incorporate labour adjustment costs, following the description of our approach given above. This allows us to compare across comparable models, one with and one without explicit modelling of adjustment costs.

For both variants, the modelling strategy is the same; calibration to an initial benchmark data set and counterfactual equilibrium analysis using the model specification generated through calibration, as in conventional applied general equilibrium analysis (see Shoven and Whalley (1992)). The models are static and incorporate the three regions: the U.S., Mexico, and the Rest-of-the-World (ROW). Only the U.S. and Mexico are modelled in detail, drawing on data contained in social accounting matrices (SAMs) for each of the regions for 1988. The ROW is modelled schematically with each industry's output set at three times that of the U.S. in the base data, and with no intermediate production or separate capital and labour components in value added.

Nine sectors (commodities) are specified: agriculture, steel, local autos ${ }^{2}$, transplant autos ${ }^{2}$, textiles and clothing, other manufactures, crude petroleum and natural gas, services

${ }^{2}$ This distinction enters the model because of its focus on NAFTA, and its earlier use in evaluating the impact of new NAFTA trade rules which discriminate between auto production based on the degree of local content. 
and other goods. Each sector produces output according to a constant returns to scale technology. Domestic and imported commodities are assumed to be imperfect substitutes, and are modelled using the Armington assumption (see Armington (1969)). Domestic and exported commodities are assumed to be homogeneous.

Production in the U.S. and Mexico follows a Leontief specification both between intermediate outputs, and between intermediates and value-added. Value-added, in turn, is produced by two primary factors - capital and labour - using a constant elasticity of substitution (CES) specification. For each intermediate, CES sub-aggregators are used; first across similar foreign produced intermediates, yielding a composite foreign intermediate product, and then aggregating the composite foreign intermediate and the similar domestic intermediate product. Production in the ROW is modelled as a constant elasticity of transformation (CEI) function that converts aggregate GDP into the various commodities specified in the model.

On the demand side of the model, there is a single representative consumer in each region with a CES utility function defined over eight commodity aggregates: agriculture, steel, autos, textiles and clothing, other manufactures, crude petroleum and natural gas, services, and other goods. Within the auto aggregate, the utility function has a CES subaggregator covering local autos and transplant autos. Within each of the nine sub-aggregates, the utility function has additional CES sub-aggregators much as on the production side, first aggregating similar foreign-produced commodities, and then the composite foreign commodity and the similar domestic commodity. Trade policy interventions are incorporated into the model using tariffs, plus an explicit quota-based treatment of non-tariff barriers. 
To calibrate the with and without adjustment cost versions of the model, we use the same 1988 data base as in Trela and Whalley (forthcoming), but make a further modification because the time period for the analysis is no longer one year, as in Trela-Whalley. An assumed time horizon of 40 years for labour relocating to different industries is used, on the grounds that young workers with the majority of their working life ahead of them are most likely to be those who move in response to a trade or other shock. Thus, in making decisions to move between sectors workers compare the income differential from relocation over a 40-year working life to the once-and-for-all adjustment cost. The period assumed for the equilibrium analysis is, therefore, the remaining length of the working life for relocating labour (assumed to be 40 years). We also make the strong assumption that the economy has fully adjusted to past disturbances, and thus all intersectoral factor movements due to previous disturbances have been completed. This implies that relative to the benchmark equilibrium, no adjustment occurs if there are no policy changes or external shocks.

We aiso need to specify what it costs one U.S. worker to move from one sector to another. We assume that all workers laid off due to trade shocks are, on average, out of work for the same period. We use two alternative estimates of duration of unemployment: 31 weeks (see Bale (1976)), and 52 weeks. $^{3}$ Other components of adjustment costs, such as retraining and relocation costs, are not included in these transaction requirements estimates.

We discount incomes and expenditures in our 1988 data set over the assumed 40 years' time horizon using a 10 percent discount rate. This is used for wages, capital income,

\footnotetext{
${ }^{3} \mathrm{Jacobsen}$ (1978) and de Melo and Tarr (1988) use a duration of unemployment estimate of six months.
} 
sales, intermediate costs, imports, exports, and final demand expenditures, making the strong assumption that there is no growth over the period. Once the benchmark equilibrium data set has been constructed, calibration proceeds in the same form as in Shoven and Whalley (1992). The model is then solved in counterfactual mode, using the MPS/GE solution software code developed by Thomas Rutherford of the University of Colorado.

The models described above can be used to calculate welfare, trade, and other effects occurring from elimination of quotas and tariffs on U.S. imports. In the model variant with adjustment costs endogenously determined, welfare effects (measured using a Hicksian Equivalent Variation) are already net of adjustment costs, which are given by the value of transactions services used. In the other model variant, adjustment costs are calculated by applying assumed unemployment duration to the labour reallocations implied by the model. Welfare impacts of the policy change yielded by the model do not reflect the adjustment costs estimated extraneously in this way.

Table I reports estimates of adjustment costs under the two approaches for the removal of U.S. quotas and tariffs (on all products imported from all regions). Estimates using the general equilibrium model without the explicit treatment of adjustment costs are shown under model $I$ in columns I and II, while those using the model incorporating adjustment costs are shown under model 2 under columns III and IV. Columns I and III assume that the eamings losses of displaced workers continue for 31 weeks, while columns $\Pi$ and $\mathrm{N}$ assume they continue for 52 weeks. In all four model variants, the time horizon of migrating workers is assumed to be 40 years. 
Table 1

Adjustment Effects of Removing U.S. Quotas and Tariffs on all Products from all Regions in

Alternative Variants of the Trela-Whalley (1993) Model

\begin{tabular}{|c|c|c|c|c|}
\hline \multirow[t]{2}{*}{ - } & \multicolumn{2}{|c|}{$\begin{array}{c}\text { Model Variant } 1 \\
\text { Full Equilibrium } \\
\text { Plus Duration Estimates }\end{array}$} & \multicolumn{2}{|c|}{$\begin{array}{l}\text { Model Variant } 2 \\
\text { Estimates Using Model } \\
\text { With Adjustment Costs }\end{array}$} \\
\hline & $\begin{array}{l}\text { I } \\
\text { (31 weeks } \\
\text { duration) }^{1}\end{array}$ & $\begin{array}{c}\quad \text { II } \\
\text { (52 weeks } \\
\text { duration) }^{l}\end{array}$ & $\begin{array}{l}\text { III } \\
\text { (31 weeks } \\
\text { duration) }\end{array}$ & $\begin{array}{c}\text { IV } \\
\text { (52 weeks } \\
{\text { duration })^{1}}^{\text {durat }}\end{array}$ \\
\hline $\begin{array}{l}\text { Estimates of U.S. } \\
\text { Adjustment Cost5 } \\
\text { (Billion \$) }\end{array}$ & 7.7 & 13.0 & 6.8 & 10.4 \\
\hline
\end{tabular}

'See text for further explanation. 
Results in Table 1 show how adjustment costs using conventional full equilibrium duration methods are overestimated compared to an equilibrium approach using endogenous adjustment costs. The full equilibrium duration estimate of adjustment costs is $\$ 7.7$ billion in column I, and $\$ 13.0$ billion in column II. In contrast, $\$ 6.8$ billion and $\$ 10.4$ billion are lost to adjustment costs in results in columns III and IV.

In Table 2, we show the effects on sectoral wage rates of removing U.S. quotas and tariffs in the model variant with endogenous transactions costs. In the results reported in column I (31-week duration assumed), the expanding sectors are agriculture, local autos, transplant autos, manufacturing, crude oil and petroleum, and others, while steel and textiles are the contracting sector. Unchanged sectors include services. These sectoral characteristics are reflected in the dispersion of wages rate changes across sectors. Similar results are exhibited in column $\Pi$ (52-week duration), except there is less intersectoral movement of labour. 
Table 2

Effects on Sectoral Wages ${ }^{2}$ of Removing U.S. Quotas and Tariffs on all Products from all Regions

(in percent)

\begin{tabular}{||l|c|c||}
\hline \multirow{2}{*}{} & \multicolumn{2}{|c|}{$\begin{array}{c}\text { Estimates Using Model Variant } \\
\text { With Adjustment Costs }\end{array}$} \\
\cline { 2 - 3 } & $\begin{array}{c}\text { I } \\
\text { (31 weeks } \\
\text { duration) }\end{array}$ & $\begin{array}{c}\text { II } \\
\text { (52 weeks } \\
\text { duration })\end{array}$ \\
\hline Agriculture & 0.4 & 0.7 \\
\hline Steel & -5.1 & -8.5 \\
\hline U.S. Autos & 0.4 & 0.7 \\
\hline Transplant Autos & 0.4 & 0.7 \\
\hline Textiles & -5.1 & -8.5 \\
\hline Manufactures & 0.4 & 0.7 \\
\hline Crude Oil & 0.4 & 0.7 \\
\hline Services & 0.3 & 0.3 \\
\hline Others & 0.4 & 0.7 \\
\hline
\end{tabular}

' Relative to the consumer price index. 


\section{Conclusion}

This paper discusses the calculation of adjustment costs in models where adjustment costs are not explicitly incorporated. We emphasize differences between models which do not explicitly incorporate adjustment costs, but instead add on a separate calculation of adjustment costs based on a counterfactual calculation of a new long-run equilibrium following removal of trade barriers, and models which explicitly model such adjustments. We argue that the former tend to over-estimate adjustment costs, while the latter explicitly calculate induced dispersion in wage rates. We present a computational procedure for the explicit analysis of such adjustment costs, and present calculations based on a model of the U.S. economy which we use to analyze the potential effects of eliminating U.S. tariff and quota restrictions. Model results show both that existing calculations tend to overestimate adjustment costs (since with endogenous adjustment costs more workers move), and that in models with adjustment costs dispersion in sectoral wage rates accompanies adjustment. 


\section{Bibliography}

Armington, P.S. (1969). "A Theory of Demand for Ptoducts Distinguished by Place of Production." Intemational Money Fund Staff Papers 16, pp.159-76.

Baldwin, R., J. Mutti, and D. Richardson (1980). "Welfare Effects on United States of a Significant Multilateral Tariff Reduction." Joumal of Intermational Economics 10, pp. 405-23.

Bale, M.D. (1976). "Estimates of Trade-Displacement Costs for US Workers." Joumal of Intemational Economics 6 (August), pp.245-50.

Broadie, M. (1983). "OCTASOLV User's Guide, Systems Optimization Laboratory Technical Report." Department of Operations Research, Stanford University, pp.839.

Cline, W. et al. (1978). Trade Negotiations in the Tokyo Round: A Quantitative Assessment. Brookings Institution, Washington, D.C.

de Melo, J. and D. Tarr (1988). "Welfare Costs of U.S. Quotas in Textiles, Steel and Autos." Paper presented at a General Equilibrium Trade Policy Modelling Conference held on March 24, 1988, University of Western Ontario, London, Canada.

Foley, D. (1970). "Economic Equilibrium with Costly Marketing." Joumal of Economic Theory 2, pp.2-91.

Jacobsen, L. (1978). "Earnings Losses of Workers Displaced from Manufacturing Industries" in W. Dewald (ed.), The Impact of Intermational Trade and Investment on Employment. U.S. Department of Labour. 
Merrill, O.H. (1972). "Applications and Extensions of an Algorithm that Computes Fixed Points of Certain Upper Semi-Continuous Point to Set Mappings." Ph.D. dissertation, Department of Industrial Engineering, University of Michigan.

Nguyen T. and J. Whalley (1986). "Equilibrium Under Price Controls with Endogenous Transactions Costs." Journal of Economic Theory 39, pp.290-300.

Shoven, J. and J. Whalley (1992). Applying General Equilibrium. Cambridge University Press, Cambridge, Massachusetts.

Trela, I. and J. Whalley (forthcoming). "Differences Between Explicit and Ad Valorem Barrier Representations in Analysis of the Effects of North American Economic Integration." The World Economy.

van der Laan, G. and J.J. Talman (1979). "A Restart Algorithm for Computing Fixed Points Without an Extra Dimension." Mathemarical Programming 17, pp.74-84. 